\title{
Methodical Approach and Tools to Improve the Efficiency of Managing of the Innovation Potential in the Context of Economic Globalization
}

\author{
Sergey Mikhailovich Vasin ${ }^{1} \&$ Leyla Ayvarovna Gamidullaeva ${ }^{1}$ \\ ${ }^{1}$ Department of Economics and Management, Penza State University, Penza, Russia \\ Correspondence: Sergey Mikhailovich Vasin, Department of Economics and Management, Penza, 440026, \\ Russia. Tel: 8-937-400-2434. E-mail: pspu-met@mail.ru
}

Received: October 6, 2014 Accepted: December 15, 2014 Online Published: February 25, 2015

doi:10.5539/res.v7n3p124 URL: http://dx.doi.org/10.5539/res.v7n3p124

\begin{abstract}
The purpose of this study was to develop a methodology for assessing and justifying the tools needed to improve the efficiency of the management of innovation potential in the context of economic globalization on the example of a high-tech enterprise. The studies developed a method of estimation of innovative potential of high-tech enterprise, which differs from the comprehensive approach to the analysis proposed by foreign and Russian scientists, which allows to take into account one aspect of globalization of the economy, and to ensure greater confidence in the conditions of application of expert methods. Proposed methodological approach is based on the methodology of fuzzy set theory, matrix methods of aggregation and analysis of complex systems. The advantage of the proposed in the methodological toolkit is the ability to a coordinated use of indicators which are measured in different difficult comparative values, as well as the transparency of this evaluation. Information obtained through the procedure contains a qualitative and quantitative assessment of each element of the structure of innovative capacity, which is an effective supplement to the management of the organization and allows the supervisor to take justified and high-quality solutions to improve the innovative capacity. The proposed tool, in our opinion, is essential to assess the innovation potential in the analysis of this type in the conditions of uncertainty and incomplete information. Results of the study are universal and can be used for improving the management of all economic systems.
\end{abstract}

Keywords: innovation potential, assessment methodology, management effectiveness, high-tech enterprise

\section{Introduction}

Intellectual capital is becoming one of the key resources, the use of which is a source of innovation. L. A. Anosova, giving the definition of the term "innovation", writes the following: "It materialized the latest scientific and technical ideas. After having received recognition in the market of consumers, they, along with the science are considered in the context of globalization as the foundation, and with it as a tool to improve competitiveness and security, as well as a basic element of a new type of society, the development of which is based on knowledge (Anosova, 2010).

Globalization, by R. Robertson (Robertson \& Lechner, 1985; Robertson, 1987) is a process of ever-increasing impact on the social reality of individual countries of different factors of international importance: economic and political ties, cultural and information exchange etc.

According to some scholars there is intensification of diverse relationships throughout the world, and globalization - an extension, deepening and acceleration of global relations. Dutch researchers note (Lubbers \& Koorevaar, 1999) that globalization is the process of reducing the importance of abstract geographical distances due to the high intensity of the economic, political and socio-cultural interactions.

Under these conditions, issues of improving the competitiveness of high-tech enterprises as the main actors in the innovation process, are of particular importance.

In the context of the global economic crisis it has been factually demonstrated once again that Russian business structures have the low competitiveness. Recent data from the World Economic Forum in 2013 indicate that the index of global competitiveness (The Global Competitiveness Report, 2014), Russia ranks 64th out of 148 
countries in the world (World Economic Forum, 2014).

This is caused by many business organizations, which form the basis of the economic system in every developed country in the world, over a long period does not have the necessary investment and innovation necessary software. Making the transition of the Russian economy to investment growth, to its modernization, is rightly attributed to maximizing the opportunities of small business as well. The concept of "innovation potential" in modern terms is "a reflection of the phenomenon of conceptual innovation (Kokurin, 2001).

Currently, the formation of innovative potential in the economic literature is being given a lot of attention, but the existing information is often sketchy and has no clear explanation.

However, in spite of a sufficient number of research methods objective assessment of potential value, many methodological and methodical aspects of this important issue have not been resolved. Thus, in particular, criteria and indicators to assess the innovative potential are not justified, the basic requirements to the system of performance indicators are not developed, there is no evidence-based classification of the factors that determine the potential for innovation, as well as a universal technique to assess the level of innovation potential of the company, taking into account aspects of globalization economy.

The writing of this article is due to the diversity of perspectives and theoretical premises of foreign and domestic researchers to study the problem of innovation potential, unresolved methodological relevance of these issues. The purpose of this study is to develop a methodology for assessing and justifying the tools needed to improve the efficiency of managing the innovation potential in the context of economic globalization on the example of a high-tech enterprise.

\section{Methods}

In some cases, the innovation potential is identified with science and technology. Innovation potential is represented as "accumulated a certain amount of information on the results of scientific and technical works, inventions, design development of new equipment and products", or understood as a "system of factors and conditions necessary for the implementation of the innovation process", as well as "the ability of different sectors of the economy to produce high-tech products that meet the requirements of the world market ", which significantly narrows the scope of this important category.

In general, most researchers distinguish two main approaches to the definition of the category of "innovation potential." First, resource-based approach treats the concept as a set of resources that are used in certain socio-economic forms to produce innovative products that meet public needs. Another approach considers the innovation potential in terms of innovation performance that is actual product of the innovation process, as well as combinations of resource and efficiency aspects.

According to D. I. Kokurin, the consideration of the essence of the innovation capacity should be treated as an economic category, which is a hierarchically organized system of concepts that are in varying degrees of approximation to the essence of potential (Kokurin, 2001). In this case, in this concept is revealed as set of categories which are not original but consequential namely subordinated and coordinated relatively to each other depending on the economic relations that they reflect that characterizes the essence of multi-level innovation capacity. In the structure of the innovative capacity of the researcher highlights: the resource potential of innovation activity; the innovation process (second level) and material production (the third level of economic relations).

In our understanding of the innovation potential (IP) we refer to a collection of innovative resources, presented in the form of product innovation, which is in turn a new resource in the innovation process.

All interpretations of the concept of innovation potential can be reduced to one aspect — necessity of existence of components of the innovation organization.

The set of components that form the innovative potential is divided into two types:

a) Necessary-required for the implementation of any kind of innovation, having the same type of parametric characteristics and common performance indicators;

b) Specific-components, composition, structure, parametric characteristics and quality indicators that define meaningful aspects of specific types of innovation (innovative types of functional components of the organization's activities-production, marketing, scientific, commercial, etc.).

Global science, including domestic, has a wide range of assessment procedures that are used in various branches of knowledge, analyze the system of all classes and serve many purposes. But in spite of this diversity, there is a gap, which is manifested in the absence of specific methods to assess the innovative capacity of the enterprise. 
To achieve the objective of the present study we suggest the use of a combination of methods, logical methods and means used in the arsenal of methods using a systematic approach and the design of complex objects, including lax based on subjective judgment, which, in practice and in theory, is united by the concept of "systems analysis."

As it is known from the theory of systems analysis, any problematic situation can be described verbally, that is verbally or formal-using special mathematical expressions. As can be seen, the presence of the definition of innovative capacity is not sufficient to calculate the value and quantitative characteristics. Therefore, the first step in solving the problem of the study is to translate the verbal description of the innovation capacity in the formal.

To solve the problem of translation of verbal descriptions into formal in different areas special tools and techniques are used. These are methods such as "brainstorming", "script", expert assessments, "objectives tree", etc.

In turn, the development of mathematics in the expansion of means of formulating and solving ambiguous problems, along with deterministic, analytical methods of classical mathematics has led to the theory of probability and mathematical statistics. For problems with a high degree of uncertainty are involved such spheres as the theory of sets, mathematical logic, mathematical linguistics, theory of graphs.

Thus, among the informal, imaginative human thinking and formal models of classical mathematics we can highlight a number of techniques that help on the one hand to formalize the verbal description of the problem situation, and on the other hand interpret formal models, connecting them with the reality.

For purposes of analysis, it is convenient to divide the methods used in the evaluation of IP enterprise, into two great classes: quantitative and qualitative methods. This separation method meets the basic requirements of the system analysis, which consists of the models and techniques of formal and informal representations, which helps in the development of methods, choice of methods of gradual formalization of the display and analysis of the problem situation.

Quantitative methods are based on the mathematical formalism. When choosing a method, it is important to understand the characteristics of the different areas and the possibility of its use in the evaluation of IP enterprise. The choice of the appropriate method is important stage in the process of analyzing the IP. It should be noted that the errors at this stage can have a significant impact on the future course of work, make it longer or lead to a standstill when the administrative decision will not be taken.

The main purpose of developing a comprehensive and systematic assessment of the innovative capacity of organizations is to develop concrete and practical recommendations for stimulating innovation.

Depending on the type of economic system we can b trace peculiarities of IP, but overall it plays a major role in its development, as an indicator, which measures the current state of affairs and prospects for growth.

In general, the task of developing a methodology for assessing the innovation potential must satisfy the following principles:

- The availability of a system of indicators of innovative potential;

- Universal method to apply it in different economic systems;

- Informative method;

- The possibility of building a strategy based on further action according to the method.

Selection of evaluation criteria and benchmarks are performed gradually by stages. First we investigated similar assessment methodology (Organisation for Economic Co-operation and Development (OECD), 2005; Belyaeva, 2007; Fatkhutdinov, 2006; Tomsk State University, 2004, etc.), then create a list of indicators and the basic structure is composed estimation of innovative potential.

The rating is made up of eight factors, each of which defines a company's ability to innovate with their point of view (finance, expertise, personnel, etc.). At the same time, the analysis of IP enterprise should be undertaken within a particular industry, because in different industries and even specializations same factors have a totally different meaning, respectively, different weights and interpretation.

The resulting quotient can be described as a function of several variables:

$\mathrm{Y}=\mathrm{F}(\mathrm{P} 1, \mathrm{P} 2, \mathrm{P} 3, \mathrm{P} 4, \mathrm{P} 5, \mathrm{P} 6, \mathrm{P} 7, \mathrm{P} 8)$

Where $\mathrm{P}$ performance evaluation criteria of innovation potential: 
P1—assessment of financial potential;

P2 - assessment of intellectual potential;

P3 - assessment of the organizational and management potential;

P4 - evaluation of marketing potential;

P5-assessing information and methodological potential;

P6 - assessment of the potential of commercialization of innovative projects;

P7-assessment of the state support of innovation;

P8 - assessment of the potential of foreign trade.

Evaluation of the financial strength includes an assessment of the financial condition, as well as opportunities for raising funds. This factor is one of the key in the evaluation and it helps to determine the financial ability of the enterprise to innovate. In determining the financial capacity is assessed financial activity, which, in turn, is a complex hybrid model with a variety of input data (mainly from official reports). Assessment of the financial condition of the company is also carried out in using a hybrid expert system, and includes an assessment of liquidity, profitability, property, turnover, etc. The result of evaluating the financial capacity may be an occasion to raise funds for investors to ensure development stages of innovation.

The most complicated in terms of the degree of uncertainty relations of input and output parameters, is to assess the predictive capacity. The values obtained from the assessment of intellectual potential, will help determine the capabilities of the staff of the enterprise and links with science for the implementation of innovations. Innovation is created by people, who are also the customers. Therefore it is necessary to develop human capital, make it a source of productivity and competitiveness, which implies the existence of a certain system of economic relations. In the case of a low value of intellectual potential the company in general should not be engaged in innovation, respectively, and the overall level of innovative capacity will be close to 0 .

Another key figure in the procedure is to evaluate the marketing potential. This indicator is of crucial importance in determining the innovative capacity, as it determines the capacity of the enterprise on the orientation of development on a particular consumer and the realization of innovation.

Assessment of organizational and managerial capacity is determined by the quality and coherent processes of the organization and management of the enterprise, that is, in principle, a key aspect of the study aspects of improving the management of innovative potential.

Information and methodological potential is a factor that cannot be ignored when creating a strategy of innovative development as an effective information environment contributes to the rapid adoption of quality management decisions. Commercialization of Innovation is the process of allocating funds for innovation and phase control over their expenditure, including the assessment and transfer of the completed and mastered in an industrial environment of innovation. Development of innovation is a multidimensional, costly and risky process, because the object of innovations is the intellectual product. In this regard, the process of commercialization of innovations has a significant complexity (Komkov et al., 2005).

With regard to state support of innovation activity, as evidenced by the world's leading research, it is a prevalent factor in the building innovation -based economies in many countries. In particular, we proved the relationship between the quality of the infrastructure arrangements and activity of business structures, and as a consequence, the level of socio-economic development of the country as a whole.

Foreign economic activity of enterprises is virtually impossible without adequate support from the state. Position of enterprises in the autonomous and their effective positioning in foreign markets are vulnerable and without government support remains unpromising. In this context, this type of building refers to external investment climate in the country.

Specific indicators which are proposed for evaluating each potential form are presented in Table 1. 
Table 1. Classification of indicators to measure the IP enterprise

\begin{tabular}{|c|c|c|}
\hline Type of potential & \multicolumn{2}{|c|}{ Indicators } \\
\hline \multirow{6}{*}{ 1. Financial potential } & 1.1 Absolute liquidity ratio & 1.7 The financial independence \\
\hline & 1.2 Factor critical (urgent) liquidity & 1.8 The financial strength \\
\hline & 1.3 Current ratio (cover) & 1.9 The ratio of long-term debt to \\
\hline & $\begin{array}{l}\text { 1.4 Surplus }(+) \text { or lack }(-) \text { of working } \\
\text { capital }\end{array}$ & $\begin{array}{l}\text { equity ratio } \\
1.10 \text { The index of financial leverage }\end{array}$ \\
\hline & $\begin{array}{l}1.5 \text { Surplus }(+) \text { or lack }(-) \text { of own current } \\
\text { and long-term debt sources of the inventory } \\
\text { and costs }\end{array}$ & $\begin{array}{l}1.11 \text { The ratio of the total amount } \\
\text { spent on innovation to sales of } \\
\text { innovative products. }\end{array}$ \\
\hline & $\begin{array}{l}\text { 1.6 Surplus }(+) \text { or lack }(-) \text { of the total value } \\
\text { of the main sources for the formation of } \\
\text { reserves and costs }\end{array}$ & \\
\hline \multirow{5}{*}{ 2. Intellectual potential } & 2.1 The share of scientific and technical & 2.5 Number of partner organizations \\
\hline & $\begin{array}{l}\text { experts } \\
2.2 \text { The share of personnel involved in }\end{array}$ & $\begin{array}{l}2.6 \text { Number of completed joint } \\
\text { projects }\end{array}$ \\
\hline & innovative projects & 2.7 Employee Motivation \\
\hline & $\begin{array}{l}2.3 \text { Indicator training of scientific } \\
\text { personnel }\end{array}$ & $\begin{array}{l}2.8 \text { The number of current joint } \\
\text { projects }\end{array}$ \\
\hline & $\begin{array}{l}\text { 2.4 The share of scientific and technical } \\
\text { personnel under the age of } 35 \text { years }\end{array}$ & 2.9 Organization of staff training \\
\hline \multirow{3}{*}{$\begin{array}{l}\text { 3. Organizational and } \\
\text { management potential }\end{array}$} & 3.1 The ability of employees to organize & 3.4 Social and communication skills \\
\hline & $\begin{array}{l}\text { and plan work } \\
\text { 3.2 Professional competence }\end{array}$ & $\begin{array}{l}3.5 \text { Manager's competence for } \\
\text { innovation }\end{array}$ \\
\hline & 3.3 Capacity for innovation & 3.5 Quality Management System \\
\hline \multirow{4}{*}{ 4. Marketing potential } & 4.1 Presence and number of representations & in the region, country, abroad \\
\hline & $\begin{array}{l}\text { of the organization in the region, country, } \\
\text { abroad }\end{array}$ & 4.4 Share of the regional market \\
\hline & $\begin{array}{l}\text { 4.2 The share of state orders in the total } \\
\text { production }\end{array}$ & $\begin{array}{l}4.5 \text { The flexibility of the marketing } \\
\text { policy }\end{array}$ \\
\hline & $\begin{array}{l}4.3 \text { The number of organizations } \\
\text { competing }\end{array}$ & \\
\hline \multirow{7}{*}{$\begin{array}{l}\text { 5.Information and } \\
\text { methodological potential }\end{array}$} & $\begin{array}{l}\text { 5.1 The use of complex automated } \\
\text { analytical systems }\end{array}$ & $\begin{array}{l}5.8 \text { Automation of manufacturing } \\
\text { planning, costing }\end{array}$ \\
\hline & 5.2 Of workstations & 5.9 The use of automated systems in \\
\hline & 5.3 Automation departments & the design and departments \\
\hline & $\begin{array}{l}\text { 5.4 Automation of accounting and financial } \\
\text { accounting }\end{array}$ & $\begin{array}{l}\text { 5.10 Development and application } \\
\text { of its own programs }\end{array}$ \\
\hline & $\begin{array}{l}5.5 \text { Automating of personnel records and } \\
\text { payroll }\end{array}$ & $\begin{array}{l}5.11 \quad \text { Interaction with the } \\
\text { information infrastructure }\end{array}$ \\
\hline & $\begin{array}{l}\text { 5.6 Organization of the system of } \\
\text { controlling }\end{array}$ & $\begin{array}{l}5.12 \text { Access to global information } \\
\text { resources }\end{array}$ \\
\hline & 5.7 Automation of management accounting & \\
\hline
\end{tabular}




\begin{tabular}{|c|c|c|}
\hline \multirow{3}{*}{$\begin{array}{l}6 . \quad \text { The potential } \\
\text { commercialization } \\
\text { innovative projects }\end{array}$} & $\begin{array}{l}6.1 \text { Number of projects completed during } \\
\text { the study period }\end{array}$ & $\begin{array}{l}\text { certificates for the study period } \\
6.5 \text { Number of licensing agreements }\end{array}$ \\
\hline & $\begin{array}{l}\text { 6.2 Duration of the innovation } \\
6.3 \text { Number of projects completed during } \\
\text { the study period }\end{array}$ & $\begin{array}{l}\text { 6.6 Number of developed } \\
\text { experimental samples }\end{array}$ \\
\hline & 6.4 Number of patents and copyright & \\
\hline \multirow{3}{*}{$\begin{array}{l}\text { 7. The state support of } \\
\text { innovation }\end{array}$} & 7.1 Benefits for taxation & financing of innovation \\
\hline & $\begin{array}{l}\text { 7.2 Availability of legal barriers } \\
7.3 \text { Access to innovation infrastructure }\end{array}$ & $\begin{array}{l}7.5 \text { The presence of a competitive } \\
\text { environment }\end{array}$ \\
\hline & 7.4 Access to funds of public & 7.6 Level of administrative barriers \\
\hline $\begin{array}{l}\text { 8. The potential of foreign } \\
\text { economic activity }\end{array}$ & $\begin{array}{l}\text { 8.1 The impact of international competition } \\
8.2 \text { Achieved technological level of } \\
\text { industry }\end{array}$ & $\begin{array}{l}8.3 \text { The level of concentration in the } \\
\text { international markets }\end{array}$ \\
\hline
\end{tabular}

To assess the innovative potential of the organization the following reporting forms are used: the balance sheet; application to the balance sheet; report on the cash flows; report on the income and expenditure; form of statistical observation number 4-innovation "Information about the innovation activities of the organization"; form of statistical observation number 2-SE innovation "Information on the technological innovations of small businesses." It is also necessary to carry out a survey for expert assessment of factors that are not quantifiable.

The system of indicators to assess the resource potential of the innovation is determined individually for study organization in accordance with the goals and objectives for innovation and its own specificity. Indicators can be both absolute and relative, measured in different measurement units (natural units, units of cost and of interest).

It is obvious that a simple analysis of the components and resources does not provide full information on the level of development of innovative potential of the economic system. We need a toolkit, allowing us to summarize estimates of parameters characterizing ingredients and components in one complex, whose value gives an indication of the level of development of innovative potential of the organization, the degree of its readiness to innovation activity and on the basis of the information received to develop management strategies.

Thus, the estimation of innovative potential should be based on a specific system of indicators using a set of methods and tools for their processing, analyzing and producing qualitative conclusions.

Practice shows that it is advisable to assess the innovative potential of performed using models that could be carried out the analysis on real processes. On this basis, it becomes necessary to develop approaches to modeling a mechanism for evaluating innovative capacity based on an analysis of its constituent elements.

Indicators to assess types of resources indirectly affect the innovation potential. In fact they determine the value of the final figure, as in the aggregate of the measure on the basis of which the supervisor concludes if the security system possesses internal resources, then determines the feasibility and success of innovation implementation, develops innovative project. To start an assessment of innovation potential we must begin with an assessment of internal resources, and only then to assess the relationship of the object with the environment.

We represent original model innovation potential (IP) of the enterprise in the following form:

$$
\mathrm{IP}=\{\mathrm{S} ; \mathrm{n}\}
$$

Where $\mathrm{S}=\{\mathrm{P} 1, \mathrm{P} 2, \mathrm{P} 3, \mathrm{P} 4, \mathrm{P} 5, \mathrm{P} 6, \mathrm{P} 7, \mathrm{P} 8\}$;

$\mathrm{IP}$-indicator of innovative potential;

$\mathrm{S}$ - resource types of innovative potential.

For innovative capacity in organizations:

P1—assessment of financial capacity;

P2 - assessment of intellectual potential;

P3 - assessment of organizational and managerial capacities;

$\mathrm{P} 4$ - assessment of marketing potential; 
P5-assessment of information and methodological potential;

P6 - assessment of the potential referring to innovative project commercialization;

P7-assessment of the state support of innovation;

P8 - assessment of the potential of foreign trade.

$\mathrm{N}=\{(\mathrm{p} 1 \mathrm{i} \ldots \mathrm{p} 1 \mathrm{n}) ;(\mathrm{p} 2 \mathrm{i} \ldots \mathrm{p} 2 \mathrm{n}) ;(\mathrm{p} 3 \mathrm{i} \ldots \mathrm{p} 3 \mathrm{n}) ;(\mathrm{p} 4 \mathrm{i} \ldots \mathrm{p} 4 \mathrm{n}) ;(\mathrm{p} 5 \mathrm{i} \ldots \mathrm{p} 5 \mathrm{n}) ;(\mathrm{p} 6 \mathrm{i} \ldots \mathrm{p} 6 \mathrm{n}) ;(\mathrm{p} 7 \mathrm{i} \ldots \mathrm{p} 7 \mathrm{n}) ;(\mathrm{p} 8 \mathrm{i} \ldots$ $\mathrm{p} 8 \mathrm{n})\}$-indicators for assessment of the component.

We represent the set of components of the innovation potential in the form of a hierarchical tree (graph) in which each level can be characterized by their classification features. The hierarchy will be denoted with a symbol G.

Hierarchy-it is a way of building and organization of complex systems, especially systems of management of economic entities, in which the elements of the system are distributing through the levels, and the whole system becomes a multi-level, having at the same time the property of integrity. Therefore, SP can be representing as a hierarchy of features:

$$
\mathrm{IP}=\mathrm{G}(\mathrm{S}, \mathrm{P})
$$

Where G-a symbol of hierarchy.

Assessment of innovative potential within such a hierarchy should be planned, beginning with the elements of the lower levels and ending with top-level elements. In the G hierarchy, in which the root element at the zero level is the indicator of innovation potential, on the first level there are resources on the second level there are indicators to measure each type of resource.

In most cases, the person who has to make decisions, is seeking to establish a logical connection between quantitative values of the indicators of a selected group with a value of innovation capacity. The task is complicated by the fact that indicators are numerous and they often vary in different directions, and therefore we must strive to keep the set of all test parameters in a complex indicator, the value of which reveals the level of innovation development and the state of innovation potential. It is necessary to note that the rate of innovation potential IP must be integral. In other words, the set of possible values of the SP should be presented in the form of intervals, each of which should give a qualitative picture of the state of IP. Under this approach, evaluation of innovative capacity will be reduced to the evaluation of the root element of the hierarchy G. We are to work out common approach to the analysis of these hierarchies, based on the methodology of fuzzy set theory, matrix methods of aggregation and analysis of complex systems

We introduce a number of variables which will bear characteristic statements. Linguistic variable is a variable which values are words or phrases of a natural language. To estimate the values of the linguistic variable the terms are used. A term - refers to any element of a term set. The term set is the set of all values of the linguistic variable.

We introduce the following set of linguistic variables with their term-set of values: The ratio of accessories $=$ \{Own, most likely belongs, probably belongs, probably does not belong to, most likely does not belong, do not belong\}.

Variable contains an arbitrary number of diverse values, ranked by strength (weakness) in a certain order. The bearer of these variables will be the unit interval. Since fuzzy knowledge is determined by linguistic variables, then the logical conclusion can be quantified on the basis of transactions with appropriate membership functions.

We represent the possible values of the indicator "innovation potential" in the form of intersecting sets. The intervals intersection index will be seen as characterizing the transition states from one property to another, and taking into account the mental activity of the expert conducting the study. These sets are typical examples of indistinct sets.

Fuzzy evaluation is currently gaining more popularity among the authors engaged in economic research, as they allow to qualitatively and quantitatively assess the indicators, measured in disparate values.

The fuzzy set A refers to the set of values of the indicator, and each its value is associated to the degree of membership of this value to any set A.

In order to take into account the mental activity of experts and their differences of opinion as to the qualitative characteristics of a quantitative value of this indicator, each fuzzy subset will be identified with its own membership function. Membership function - a feature that allows for an arbitrary element of the universal set to determine the degree of indistinct sets. Ranges of the functions - the unit interval. We are to form a linguistic variable with a term-set of possible qualitative assessments of the level of any of the elements or indicators 
included in the model of innovation capacity L $=\{$ Very Low (VL), Low (L), Medium (M), High level (H), Very high $(\mathrm{VH})$ \}.

Model innovation potential takes the form:

$$
\mathrm{IP}=\mathrm{G}[\mathrm{s}(\mathrm{P} 1, \mathrm{P} 2, \mathrm{P} 3, \mathrm{P} 4, \mathrm{P} 5, \mathrm{P} 6, \mathrm{P} 7, \mathrm{P} 8), \text { П, L }]
$$

With such a formulation of the problem in the development of methodology for assessing the innovation potential of the important role belongs to the choice of the scale comparison of numerical values of the quantity of possible qualitative characteristics. As the scale it is proposed to use a standard five-level 01-fuzzy classifier with membership functions suggested in the works of Nedosekin (2011).

$$
\begin{aligned}
& \mu_{1}(x)=\left\{\begin{array}{c}
1,0 \leq x<0.15 \\
10(0.25-x), 0.15 \leq x<0.25 \\
0,0.25 \leq x \leq 1
\end{array}\right. \\
& \mu_{2}(x)=\left\{\begin{array}{c}
0,0 \leq x<0.15 \\
10(x-0.25), 0.15 \leq x<0.25 \\
1,0.25 \leq x<0.35 \\
10(0.45-x), 0.35 \leq x<0.45 \\
0,0.45 \leq x \leq 1
\end{array}\right. \\
& \mu_{3}(x)=\left\{\begin{array}{r}
0,0 \leq x<0.35 \\
10(x-0.35), 0.35 \leq x<0.45 \\
1,0.45 \leq x<0.55 \\
10(0.65-x), 0.55 \leq x<0.65 \\
0,0.65 \leq x \leq 1
\end{array}\right. \\
& \mu_{5}(x)=\left\{\begin{array}{r}
10(x-0.75), 0.75 \leq x<0.85 \\
1,0.85 \leq x \leq 1
\end{array}\right. \\
& \mu_{4}(x)=\left\{\begin{array}{r}
0,0 \leq x<0.55 \\
10(x-0.55), 0.55 \leq x<0.65 \\
1,0.65 \leq x<0.75 \\
10(0.85-x), 0.75 \leq x<0.85 \\
0,0.85 \leq x \leq 1
\end{array}\right. \\
& 0,0 \leq x<0.75 \\
& 0
\end{aligned}
$$

The essence of the classifier that if the indicator is unknown except that it can take any value within a 01-carrier, and it is necessary to carry out the association between the qualitative and quantitative assessment of the indicators, the proposed classifier performs the function with maximum reliability. The sum of all the membership functions for each $\mathrm{X}$ is equal to one, indicating the consistency of the classifier.

Classification of elements of the hierarchy is takes the following order. The challenge is to create a symmetrical five distinct intervals, each of which is defined by its term of term-sets of the form L. For each of the elements of the second level of the hierarchy characterizing their view resources two normative values are defined corresponding to the lower (c1) and high (c2), and is calculated by the formula length classification intervals $\alpha$ :

$$
\alpha=\frac{c_{1}-c_{2}}{3}
$$


The interval for this becomes: $\{$ Very low $-<\mathrm{c} 1$; Low $-[\mathrm{c} 1 ; \mathrm{c} 1+\alpha)$; Medium $-[\mathrm{c} 1+\alpha, \mathrm{c} 1+2 \alpha)$; High $-[\mathrm{c} 1 \times 2 \alpha$, c2]; Very High $\longrightarrow$ c2 $\}$

Further data ranges can be specified directly by the expert or leader in accordance with the specifics, the study of the economic system and its subjective opinion.

It is obvious that if we consider the impact of the set of indicators on the common one, each component of aggregate acts in different directions. In other words, the degree of influence of the plurality of parameters is different in strength, and each of the indices will be more or less important than the other. Therefore, when assessing the innovative capacity we must take into account the importance of this in the form of weighting factors.

The hierarchical structure of innovative potential implies a fact that in its estimation, the resources are in some way alternative to each other. If you place the branch of the hierarchy in the rank in descending order of importance of each type of resource, we obtain a system of decreasing preference of the finite number of alternatives.

It is known that the system of decreasing preference alternatives best fits the system of reduced scales by the rule of the arithmetic progression of Fishbern (1978):

$$
p_{i}=\frac{2(m-i+1)}{(m+1) m}
$$

Where $\mathrm{i}=1 \ldots \mathrm{m}$, and for system of indifferent to each other $\mathrm{m}$ alternatives $-\mathrm{a}$ set of equal weights: $p_{i=} m^{-1}$,где $\mathrm{I}=1 \ldots \mathrm{m}(7)$.

To determine a set of weights of Fishbern for a mixed system preferences, when along with the preferences, the system includes an attitude of indifference, it is necessary to determine the numerators $r_{i}$ rational fractions on a recursive scheme:

$$
r_{i-1}=\left\{\begin{array}{c}
r_{1}, F_{i-1} \approx F_{i} \\
r_{i}+1, F_{i-1} \succ F_{i}
\end{array}, r_{N}=1, i=m \ldots 2\right.
$$

Then the sum of the received numerators is a common denominator fraction of Fishbern:

$$
\begin{gathered}
K=\sum_{i=1}^{m} r_{i} \\
p_{i}=\frac{r_{i}}{K}
\end{gathered}
$$

Next, we will estimate the rate of innovation potential on the basis of aggregate values of all levels of the hierarchy. Aggregation - a consolidation of economic indicators by means of combining them into a group. Aggregates represent generalized, synthetic measurement, uniting in a common indicator an amount of private ones. Values of the types of innovation potential resources is aggregate indicators referring to their elements of the second-level G, and the innovative potential is an aggregate indicator relatively to its constituents.

We introduce the indicator $\mathrm{R}=\{\mathrm{r} 1, \mathrm{r} 2, \mathrm{r} 3, \mathrm{r} 4, \mathrm{r} 5\}$-degree of membership, which values $\mathrm{r} 1, \mathrm{r} 2, \mathrm{r} 3, \mathrm{r} 4, \mathrm{r} 5$ will be equal to either 0 or 1 , where in the sum of these values must always be equal to one. In other words, from a set of values $\mathrm{r} 1, \mathrm{r} 2, \mathrm{r} 3, \mathrm{r} 4, \mathrm{r} 5$, only one will take a value equal to one and the rest will be correspondingly equal to zero. The element " 0 " means that the calculated value of the element does not belong to a given interval, and "1"- - means it belonging to it. Since every term of a set L in each index has its own range, then, for example, the estimated value of the index, characterized as "high" will be described as the indicator R $\left(\begin{array}{lllll}0 & 0 & 0 & 1 & 0\end{array}\right)$. From this follows that each calculated value of the element of the second hierarchical level can be written in terms of R, and meets one of the conditions:

- Very low value of the index corresponds to the value of the indicator R1 $\left(\begin{array}{llll}1 & 0 & 0 & 0\end{array}\right)$;

- Low value of the index corresponds to the value of the indicator R2 (l $\left.\begin{array}{llll}0 & 1 & 0 & 0\end{array}\right)$;

- Medium Very low value of the index corresponds to the value of the indicator R3 $\left(\begin{array}{lllll}0 & 0 & 1 & 0 & 0\end{array}\right)$;

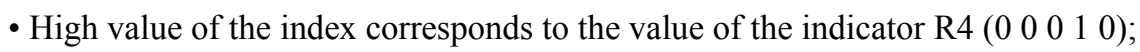

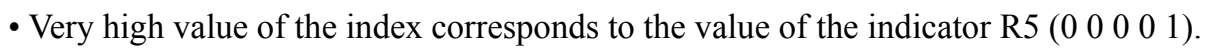


Since each type of resource is represented by a set of indexes, the level of the component can be represented as a matrix, which we call the matrix classification. Rows of the matrix will consist of sets of $\mathrm{R}$, corresponding to the value of each index assessment.

Next, it is necessary to obtain the numerical values of the components that could be described by terms of the set $\mathrm{L}$ and recognize the classifier.

It is known that the aggregation is carried out by adding, grouping or other means of private information in the summary of index values.

Within each of these resources using the circuits of weights by Fishbern weighting coefficients are determined between their own values. Vertices $\left(\begin{array}{lllll}0.1 & 0.3 & 0.5 & 0.7 & 0.9\end{array}\right)$ of the standard fuzzy classifier act as an aggregate system of weights, allowing to estimate the matrix composed of a set of $\mathrm{R}$ classifier. Then the formula for calculating the values of the components will be:

$$
\begin{aligned}
& S=\left(p_{1} \ldots p_{m}\right) \times\left(\begin{array}{ccccc}
r_{11} & r_{12} & r_{13} & r_{14} & r_{15} \\
r_{21} & r_{22} & r_{23} & r_{24} & r_{25} \\
r_{31} & r_{32} & r_{33} & r_{34} & r_{35} \\
\ldots & \ldots & \ldots & \ldots & \ldots \\
r_{m 1} & r_{m 2} & r_{m 3} & r_{m 4} & r_{m 5}
\end{array}\right) \times\left(\begin{array}{c}
0,1 \\
0,3 \\
0,5 \\
0,7 \\
0,9
\end{array}\right)= \\
& 0,1 \times \sum_{i=1, j=1}^{m} p_{j} r_{i 1}+0,3 \times \sum_{i=1, j=1}^{m} p_{j} r_{i 2}+0,5 \times \sum_{i=1, j=1}^{m} p_{j} r_{i 3}+0,7 \times \sum_{i=1, j=1}^{m} p_{j} r_{i 4}+0,9 \times \sum_{i=1, j=1}^{m} p_{j} r_{i 5}
\end{aligned}
$$

Innovation potential is calculated as the aggregate relative to the values P1... P8. The formula for calculating IP takes the form:

$$
\mathrm{IP}=\sum_{\mathrm{k}=1}^{8} \mathrm{w}_{\mathrm{k}} \mathrm{S}_{\mathrm{k}}
$$

Qualitative assessment of the quantitative index is based on the classification of the table values (Table 2.).

Table 2. Classification level IP, S

\begin{tabular}{lll}
\hline Interval of value IP, $\mathrm{S}$ & Classification of level IP, $\mathrm{S}$ & $\begin{array}{l}\text { The degree of confidence evaluation of } \\
\text { belonging to the interval } 100 \%, \mu\end{array}$ \\
\hline $0 \leq \mathrm{IP}, \mathrm{S} \leq 0.15$ & The five-level standard 01-classifier \\
$0.15 \leq \mathrm{IP}, \mathrm{S} \leq 0.25$ & Very low & 1 \\
& Very low & $\mu 1=10 \times(0.25-\mathrm{IP}, \mathrm{S})$ \\
$0.25<\mathrm{IP}, \mathrm{S}<0.35$ & Low & $1-\mu 1=\mu 2$ \\
$0.35 \leq \mathrm{IP}, \mathrm{S} \leq 0.45$ & Low & 1 \\
$0.45<\mathrm{IP}, \mathrm{S} \leq 0.55$ & Low & $\mu 2=10 \times(0.45-\mathrm{IP}, \mathrm{S})$ \\
$0.55<\mathrm{IP}, \mathrm{S} \leq 0.65$ & Medium & $1-\mu 2=\mu 3$ \\
$0.65<\mathrm{IP}, \mathrm{S} \leq 0.75$ & Medium & 1 \\
$0.75<\mathrm{IP}, \mathrm{S} \leq 085$ & Medium & $\mu 3=10 \times(0.65-\mathrm{IP}, \mathrm{S})$ \\
$0.85<\mathrm{IP}, \mathrm{S}<1$ & High & $1-\mu 3=\mu 4$ \\
& High & 1 \\
\hline
\end{tabular}

The result is a linguistic description of the innovative capacity of the organization and the confidence in the correctness of the expert recognition, thus the conclusion by the level of innovation potential has not only linguistic form, but also the characterization of the quality of the statements. 


\section{Results}

Assessment of indicators shall refer to a particular high-tech company (Table 3).

Table 3. Assessment of indicators of innovative potential of the company

\begin{tabular}{|c|c|c|c|}
\hline Indicators & Assessment & Therm & The type of indicator \\
\hline \multicolumn{4}{|l|}{ 1. Financial potential } \\
\hline 1.1 Absolute liquidity ratio & 0.39 & M & $\mathrm{R} 3\left(\begin{array}{lllll}0 & 0 & 1 & 0 & 0\end{array}\right)$ \\
\hline 1.2 Factor critical (urgent) liquidity & 1.2 & M & $\mathrm{R} 3\left(\begin{array}{lllll}0 & 0 & 1 & 0 & 0\end{array}\right)$ \\
\hline 1.3 Current ratio (cover) & 1.821 & $\mathrm{H}$ & $\mathrm{R} 4\left(\begin{array}{lllll}0 & 0 & 0 & 1 & 0\end{array}\right)$ \\
\hline 1.4 Surplus $(+)$ or lack $(-)$ of working capital & - & $\mathrm{VL}$ & $\mathrm{R} 1\left(\begin{array}{lllll}1 & 0 & 0 & 0 & 0\end{array}\right)$ \\
\hline $\begin{array}{l}1.5 \text { Surplus }(+) \text { or lack }(-) \text { of own current and long-term debt } \\
\text { sources of the inventory and costs }\end{array}$ & - & $\mathrm{VL}$ & $\mathrm{R} 1\left(\begin{array}{lllll}1 & 0 & 0 & 0 & 0\end{array}\right)$ \\
\hline $\begin{array}{l}\text { 1.6 Surplus }(+) \text { or lack }(-) \text { of the total value of the main sources for } \\
\text { the formation of reserves and costs }\end{array}$ & + & $\mathrm{VH}$ & $\mathrm{R} 5\left(\begin{array}{llllllllll}0 & 0 & 0 & 0 & 1\end{array}\right)$ \\
\hline 1.7 The financial independence & 0.750 & M & $\mathrm{R} 3\left(\begin{array}{lllll}0 & 0 & 1 & 0 & 0\end{array}\right)$ \\
\hline 1.8 The financial strength & 0.22 & $\mathrm{M}$ & $\mathrm{R} 3\left(\begin{array}{lllll}0 & 0 & 1 & 0 & 0\end{array}\right)$ \\
\hline 1.9 The ratio of long-term debt to equity ratio & 0.032 & $\mathrm{H}$ & $\mathrm{R} 4\left(\begin{array}{lllll}0 & 0 & 0 & 1 & 0\end{array}\right)$ \\
\hline 1.10 The index of financial leverage & 1.431 & $\mathrm{VH}$ & $\mathrm{R} 5\left(\begin{array}{lllll}0 & 0 & 0 & 0 & 1\end{array}\right)$ \\
\hline $\begin{array}{l}1.11 \text { The ratio of the total amount spent on innovation to sales of } \\
\text { innovative products }\end{array}$ & 39.25 & M & $\mathrm{R} 3\left(\begin{array}{lllll}0 & 0 & 1 & 0 & 0\end{array}\right)$ \\
\hline \multicolumn{4}{|l|}{ 2. Intellectual potential } \\
\hline 2.1 The share of scientific and technical experts & 75.6 & $\mathrm{H}$ & $\mathrm{R} 4\left(\begin{array}{lllll}0 & 0 & 0 & 1 & 0\end{array}\right)$ \\
\hline 2.2 The share of personnel involved in innovative projects & 28.9 & $\mathrm{~L}$ & $\mathrm{R} 2\left(\begin{array}{lllll}0 & 1 & 0 & 0 & 0\end{array}\right)$ \\
\hline 2.3 Indicator training of scientific personnel & 4 & $\mathrm{~L}$ & $\mathrm{R} 2\left(\begin{array}{lllll}0 & 1 & 0 & 0 & 0\end{array}\right)$ \\
\hline $\begin{array}{l}2.4 \text { The share of scientific and technical personnel under the age of } \\
35 \text { years }\end{array}$ & 56 & M & $\mathrm{R} 3\left(\begin{array}{lllll}0 & 0 & 1 & 0 & 0\end{array}\right)$ \\
\hline 2.5 Number of partner organizations & 7 & $\mathrm{H}$ & $\mathrm{R} 4\left(\begin{array}{lllll}0 & 0 & 0 & 1 & 0\end{array}\right)$ \\
\hline 2.6 Number of completed joint projects & 15 & $\mathrm{VH}$ & $\mathrm{R} 5\left(\begin{array}{lllll}0 & 0 & 0 & 0 & 1\end{array}\right)$ \\
\hline 2.7 Employee Motivation & 4 & $\mathrm{H}$ & $\mathrm{R} 4\left(\begin{array}{lllll}0 & 0 & 0 & 1 & 0\end{array}\right)$ \\
\hline 2.8 The number of current joint projects & 3 & $\mathrm{M}$ & $\mathrm{R} 3\left(\begin{array}{lllll}0 & 0 & 1 & 0 & 0\end{array}\right)$ \\
\hline 2.9 Organization of staff training & 3 & $\mathrm{M}$ & $\mathrm{R} 3\left(\begin{array}{lllll}0 & 0 & 1 & 0 & 0\end{array}\right)$ \\
\hline \multicolumn{4}{|l|}{ 3. Organizational and management potential } \\
\hline 3.1 The ability of employees to organize and plan work & 4 & $\mathrm{H}$ & $\mathrm{R} 4\left(\begin{array}{lllll}0 & 0 & 0 & 1 & 0\end{array}\right)$ \\
\hline 3.2 Professional competence & 3 & M & $\mathrm{R} 3\left(\begin{array}{llllllllllllll}0 & 0 & 1 & 0 & 0\end{array}\right)$ \\
\hline 3.3 Capacity for innovation & 4 & $\mathrm{H}$ & $\mathrm{R} 4\left(\begin{array}{lllll}0 & 0 & 0 & 1 & 0\end{array}\right)$ \\
\hline 3.4 Social and communication skills & 4 & $\mathrm{H}$ & $\mathrm{R} 4\left(\begin{array}{lllll}0 & 0 & 0 & 1 & 0\end{array}\right)$ \\
\hline 3.5 Manager's competence for innovation & 4 & $\mathrm{H}$ & $\mathrm{R} 4\left(\begin{array}{lllll}0 & 0 & 0 & 1 & 0\end{array}\right)$ \\
\hline 3.6 Quality Management System & 4 & $\mathrm{H}$ & $\mathrm{R} 4\left(\begin{array}{lllll}0 & 0 & 0 & 1 & 0\end{array}\right)$ \\
\hline $\begin{array}{l}\text { 4. Marketing potential } \\
\text { 4.1 Presence and number of representative offices of the } \\
\text { organization in the region, in the country, abroad }\end{array}$ & & & $\mathrm{R} 1\left(\begin{array}{lllll}1 & 0 & 0 & 0 & 0\end{array}\right)$ \\
\hline 4.2 The share of state orders in the total production & - & $\mathrm{VL}$ & \\
\hline 4.3 The number of companies competing in the region, in the & - & $\mathrm{VL}$ & \\
\hline
\end{tabular}


country, abroad

4.4 Share of the regional market $-\quad \mathrm{VL}$

4.5 The flexibility of the marketing policy

35.7

R3( $\left(\begin{array}{lllll}0 & 0 & 1 & 0 & 0\end{array}\right)$

5. Information and methodological potential

5.1 The use of complex automated analytical systems

5.2 Of workstations

5.3 Automation departments

5.4 Automation of accounting and financial accounting

5.5 Automating of personnel records and payroll

5.6 Organization of the system of controlling

5.7 Automation of management accounting

5.8 Automation of manufacturing planning, costing

5.9. The use of automated systems in the design and departments

5.10 Development and application of its own programs

5.11 Interaction with the information infrastructure

5.12 Access to global information resources

6. The potential commercialization of innovative projects

6.1 Number of projects completed during the study period

6.2 Duration of the innovation

6.3 Number of projects completed during the study period

$\begin{array}{ll}2 & \mathrm{~L} \\ 4 & \\ 4 & \mathrm{H} \\ 4 & \mathrm{H} \\ 5 & \mathrm{H}\end{array}$

L

R2( $\left(\begin{array}{lllll}0 & 1 & 0 & 0 & 0\end{array}\right)$

$\mathrm{H}$

$\mathrm{R} 4\left(\begin{array}{lllll}0 & 0 & 0 & 1 & 0\end{array}\right)$

$\mathrm{H}$

$\mathrm{R} 4\left(\begin{array}{lllll}0 & 0 & 0 & 1 & 0\end{array}\right)$

$\mathrm{H}$

R4( $\left(\begin{array}{lllll}0 & 0 & 0 & 1 & 0\end{array}\right)$

$\mathrm{VH}$

R5( $\left(\begin{array}{lllll}0 & 0 & 0 & 0 & 1\end{array}\right)$

$4 \mathrm{H}$

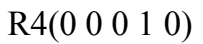

$5 \quad \mathrm{VH} \quad \mathrm{R} 5\left(\begin{array}{lllll}0 & 0 & 0 & 0 & 1\end{array}\right)$

$4 \quad \mathrm{H} \quad \mathrm{R} 4\left(\begin{array}{lllll}0 & 0 & 0 & 1 & 0\end{array}\right)$

$4 \quad \mathrm{H} \quad \mathrm{R} 4\left(\begin{array}{lllll}0 & 0 & 0 & 1 & 0\end{array}\right)$

$4 \quad \mathrm{H} \quad \mathrm{R} 4\left(\begin{array}{lllll}0 & 0 & 0 & 1 & 0\end{array}\right)$

6.4 Number of patents and copyright certificates for the study 5 period

6.5 Number of licensing agreements

7

6.6 Number of developed experimental samples

7. The state support for innovation

7.1 Benefits for taxation

$5 \quad \mathrm{VH}$

$\mathrm{R} 5\left(\begin{array}{lllll}0 & 0 & 0 & 0 & 1\end{array}\right)$

3

M

R3( $\left(\begin{array}{lllll}0 & 0 & 1 & 0 & 0\end{array}\right)$

\subsection{Availability of legal barriers}

7.3 Access to innovation infrastructure

7.4 Access to funds of public financing of innovation

7.5 The presence of a competitive environment

$\begin{array}{llll}12 & \mathrm{M} & \mathrm{R} 3\left(\begin{array}{lllll}0 & 0 & 1 & 0 & 0\end{array}\right) \\ 20 & \mathrm{H} & \mathrm{R} 4\left(\begin{array}{lllll}0 & 0 & 0 & 1 & 0\end{array}\right) \\ 17 & \mathrm{H} & \mathrm{R} 4\left(\begin{array}{lllll}0 & 0 & 0 & 1 & 0\end{array}\right) \\ 5 & \mathrm{~L} & \mathrm{R} 2\left(\begin{array}{lllll}0 & 1 & 0 & 0 & 0\end{array}\right)\end{array}$

7.6 Level of administrative barriers

8. The potential of foreign economic activity

8.1 The impact of international competition

8.2 Achieved technological level of industry

8.3 The level of concentration in the international markets

$\begin{array}{ll}7 & \mathrm{M} \\ 1 & \mathrm{~V}\end{array}$

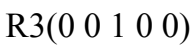

VL $\quad$ R1( $\left(\begin{array}{lllll}1 & 0 & 0 & 0 & 0\end{array}\right)$

To determine the weighting coefficients we used a system indifferent values. Following values were obtained P1-P8, showing innovation potential. We have summarized the results of the level assessing of the components in the Table 4. 
Table 4. Level of the components of the innovative potential of high-tech company

\begin{tabular}{lllc}
\hline \multicolumn{1}{c}{ Indicators } & Assessment & Therm & The type of indicator \\
\hline Financial potential & 0,5362 & $\mathrm{M}$ & $\mathrm{P} 1$ \\
Intellectual potential & 0,644 & $\mathrm{H}$ & $\mathrm{P} 2$ \\
Organizational and management potential & 0,663 & $\mathrm{H}$ & $\mathrm{P} 3$ \\
Marketing potential & 0,42 & $\mathrm{M}$ & $\mathrm{P} 4$ \\
Information and methodological potential & 0,74 & $\mathrm{H}$ & $\mathrm{P} 5$ \\
The potential commercialization of innovative projects & 0,467 & $\mathrm{CM}$ & $\mathrm{P} 6$ \\
The state support of innovation & 0,67 & $\mathrm{H}$ & $\mathrm{P} 7$ \\
The potential of foreign economic activity & 0,566 & $\mathrm{M}$ & $\mathrm{P} 8$ \\
\hline
\end{tabular}

According to the results it can be judged that the company has a level of innovation potential corresponding to the intermediate value between the terms $\mathrm{M}-\mathrm{H}$. The lowest levels were demonstrated the marketing potential and the potential commercialization of innovative projects. This circumstance is unacceptable in a complex competitive environment of economic globalization. To improve the efficiency of data management of innovation capacity should be offered the following set of activities:

- Clarification of the market position of the company and its place in the market by an actual arsenal of methods of strategic management, in particular the SWOT-analysis, the matrix BCG, GE and McKinsey and others;

- Analysis of the target market of innovation and determination of market opportunities of the company by using Ansoff matrix;

- Carrying out the actions of marketing complex;

- Active participation in exhibitions;

- Organization of training and retraining;

- Promotion of creative work, including rationalization and invention, and others.

\section{Discussion}

Modern Russian and foreign researchers pay significant attention to development of approaches, methodologies, tools and mechanisms to assess the innovative potential of enterprises. Some of them offer to use only quantitative indicators to measure IP. However, this approach does not allow taking into account the variety of factors that contribute to the formation and development of innovative potential of the modern enterprise. Without the use of expert assessments and sociological research on this issue it is not sufficient. In particular, such methods are used in practice, both abroad and in Russia. Among them, the methodological approaches to the assessment of innovation potential "Oslo Manual" (Oslo Manual, 2005), Balanced Scorecard (Kaplan \& Norton, 2001), the technique of European Commission (European Commission, 2004), and others (Eurostat, 2006; United Nations, 2001 etc.). Among domestic procedures should be mentioned innovative potential assessment methodology developed by Belyaeva (2007), Trifilova (2005), Pancheva (2006), Nurgaliyeva (2008) and others. However, in our opinion the use of these techniques does not allow to avoid the inherent subjectivity in the evaluation of qualitative factors affecting the innovation potential of the economic system. The insufficiency of completeness or accuracy of the initial information often leads to ambiguities in determining the final outcome of the assessment of the potential. Therefore, to ensure the reliability of the obtained findings we consider it appropriate to use as a tool for identifying values of IP fuzzy multiple descriptions, which consist in replacing of the point numeric values on their qualitative characteristics. At the same time, we consider the scale of the possible point numerical estimates of innovative potential as an interval in the form of a standard five-level fuzzy classifier.

Thus, our proposed method for estimating the innovative potential on the basis of expert judgment can be used to evaluate the innovative capacity of the various systems. At the same time components characterizing the system form a hierarchy of elements and the factors of a sublevel of the hierarchy are in a relationship of preference or indifference to each other. As an integrated indicator for assessing multiplicative convolution is used.

This description can be used for estimating the level of innovative potential by using aggregation factor values based on qualitative assessments of their values, as well as their relationship of the order on a level of the 
hierarchy.

The advantage of the proposed methodology of the toolkit is the ability to use the agreed indicators which are measured in diverse hard comparable values, as well as the transparency of this evaluation. According to the evaluation of the innovative potential a manager or expert should have a certain idea about the state of the object, its strengths and weaknesses, in conjunction with being identified potential growth point. Information obtained as a result of the procedure contains a qualitative and quantitative assessment of each element of the structure of innovative capacity, which is an effective supplement to the management of the organization, additionally it allows the supervisor to make informed and high-quality decisions to improve the innovative potential. The proposed tool, in our opinion, is necessary for the evaluation of innovative potential in the analysis of this type in the conditions of uncertainty and incomplete information.

\section{Conclusion}

Thus, the formation of effective levers of influence on the internal environment of the organization begins with an assessment of the innovative potential and the processing of its results in order to identify problems and areas for further development.

To establish an effective tactical management of innovation potential-a complex process that involves a significant number of different components of the system management. One of the stages of this process is to create a strategy consisting of a set of measures aimed at achieving performance gains at all levels. Using a similar strategy for the development of innovative potential to optimize tactical control system, making it "transparent" and available for the natural movement of information flows, monitoring and decision-making.

It seems necessary to control the whole process by dividing it into a number of stages that structure the problems of increasing of innovative capacity, and provide conditions for the transition and traffic information flows, and eventually monitor the decision-making process.

The first step-getting information about the situation. As the knowledge base are considered the results of evaluation of the innovative capacity of the numerical value and the linguistic description of the index IP and $\mathrm{P} 1-\mathrm{P} 8$, classification values of $\mathrm{L}$ and $\mathrm{R}$ indicators to measure the types of resources.

The second stage - the definition of goals and objectives. Only after determining the goals and objectives we can highlight factors, mechanisms, laws, resources, influencing the development of the situation. A significant role is played here by the identification of priority. According to the evaluation of the innovative potential of the expert should draw conclusion about the potential and the organization's readiness to implement innovative projects.

The third stage - the analysis and diagnosis of the situation. If you have the necessary information about the object and about a particular purpose, which the organization is striving to achieve, it is necessary to start the analysis. The purpose of this analysis is to identify the factors affecting the development of the situation. In addition, it is necessary to define the most important issues that should first pay attention to the conditions of purposeful management processes. It should also investigate the nature of the impact of these problems on these processes.

The fourth stage - analysis of prospects and forecast development. At this stage, the potential of the organization in the implementation of a particular innovative project. The key growth points and instruments of influence on them are indentified on this stage. The tasks associated with the implementation of prospects in the short and long term are being formed.

The fifth stage - the search for alternative solutions. In this process, it is necessary to make full use of information on the situation of the decision, likewise the results of the analysis and evaluation of the situation, the results of its diagnosis and prognosis of development at different possible directions of development of events. It is necessary to look beyond the obvious sets of activities, alternative ways of solving problems, which can reduce the time of implementation of a set of actions or increase the efficiency of input changes.

The sixth stage - expert evaluation of variants of administrative decisions. This assessment may be carried out both in single-player mode, and collectively. Expertise, giving a comparative evaluation of alternatives of control actions, first, characterizes the degree of feasibility of these actions, as well as the opportunity to achieve their specific goals, and secondly, makes it possible to carry out the ranking of management decisions using the existing evaluation system in accordance with a various expected level of achievement, necessary cost of labor, material and financial resources, in accordance with the most likely scenario of situations. If you make important management decisions, you should use the collective expertise that provides the greatest validity and effectiveness of decisions. 
Seventh stage - development of an action plan. At this stage, it's high time for organizational and technical measures aimed at the adoption of the sixth stage of the management decisions.

The eighth stage- formation of strategy of development. On progress made in the previous stages of the expert generates obtained previously information with the plan of activities. There is a distribution of responsibilities and instructions to all elements of management and production structure of the organization.

The ninth stage - the implementation of the developed strategy and monitoring of its implementation. Progress in implementation of the plan should be systematically monitored and any changes in conditions taking place, or deviations in the process of implementation of the plan should be systematically analyzed.

The tenth stage - analysis and evaluation of the effectiveness after taking management actions. At this stage the plan of management actions are thoroughly analyzed in order to evaluate the effectiveness of decision-making and implementation.

Prospects for the further research are represented by the following:

a) Improvement of the proposed assessment for the innovative potential of the system performance and the creation of a necessary, compulsory component of estimation of innovative potential of the company and the specific, consisting of indicators selected by enterprises in accordance with the substantive aspects of the specific types of innovation.

b) Carrying out of comparative studies of innovative potential of high-tech enterprises of the profile clusters to justify advantages over companies that operate outside these cluster structures.

c) Study of the innovative capacity of enterprises in clusters, identification and evaluation of a number of specific factors that influence the potential for innovation.

\section{References}

Anosova, L. A. (2010). Problems of Russia's transition to innovative development. Economics and management, $10,25-29$.

Belyaeva, E. S. (2007). Improving management of innovative activity of industrial enterprises based on estimation of innovative potential. Barnaul, Russia: Altai branch of the Leningrad State University.

European Commission. (2004). Innovation Management and Knowledge-Driven Economy. Brussels-Luxembourg. $\quad$ Retrieved from http://www.innovation.lv/ino2/publications/studies_innovation_management_final_report.pdf

Eurostat. (2006). SMEs and entrepreneurship in the EU. Retrieved from http://epp.eurostat.ec.europa.eu/cache/ITY_OFFPUB/KS-NP-06-024/EN/KS-NP-06-024-EN.PDF

Fatkhutdinov, R. A (2006). Innovation Management: Textbook for universities. St. Petersburg: Peter.

Fishbern, P. (1978). Utility theory for decision-making. Moscow, M.: Science.

Kaplan, R. S., \& Norton, D. P. (2001). Beyond Balanced Scorecard: The Strategic-Focused Organization. Boston: Harvard Business School Press. http://dx.doi.org/10.1177/097215090100200211

Kokurin, D. I. (2001). Innovative activity. Moscow, M.: Examination.

Komkov, N. I., Balayan, G. G., \& Bondarev, N. N. (2005). Requirements and conditions for evaluating the effectiveness of business innovation in a competitive market. Moscow, M.: Max-Press.

Lubbers, R., \& Koorevaar, I. (1999). Primary globalisation, secondary globalisation and the sustainable development paradigm, Opposing forces in the 21st Century. Berlin, Germany: Globus. Retrieved from http://www.mgimo.ru/fileserver/2004/kafedry/mirec/konf_2-12-05/primary-secondary_globaliz.pdf

Nedosekin, A. O. (2003). Methodological bases of modeling financial performance using fuzzy multiple descriptions. Saint-Petersburg State University of Economics (Doctoral dissertation). St. Petersburg, Russia.

Nedosekin, A. O. (2002). Fuzzy multiple risk analysis of stock investment. Retrieved from http:/sedok.narod.ru/index.html

Nedosekin, A. O. (2000). Application of fuzzy set theory to the problems of financial management. Audit and financial analysis, 2. Retrieved from http://www.cfin.ru

Nedosekin, A. O. (2011). Assessment of business risk based on fuzzy data. Retrieved from http:/sedok.narod.ru/index.html

Nurgaliyeva, S. M. (2008). Problems of estimation of innovative potential of the enterprise. Questions of modern 
science and practice, 11, 238-243. Retrieved from http://vernadsky.tstu.ru/pdf/2008/01g/38g.pdf

OECD. (2005). The Measurement of Scientific and Technological Activities. French. http://dx.doi.org/10.1787/19900414

Pancheva, L. A. (2006). Formation of an effective management system of innovation potential of industrial enterprise on the principles of investment and production management. Orel, Russia: Orel Regional Academy of Public Administration

Robertson, R., \& Lechner F. (1985). Modernization, globalization and the problem of culture in the world-systems theory. Theory, Culture \& Society, 2, 103-117. http://dx.doi.org/10.1177/0263276485002003009

Robertson, R. (2000). Globalization: Social Theory and Global Culture. http://dx.doi.org/10.4135/9781446280447

Trifilova, A. A. (2005). Evaluating the effectiveness of innovative development of enterprise (p. 304). Moscow: Finance and statistics.

Tomsk State University. (2004). Comprehensive assessment of the innovation potential of industrial enterprise: Guidelines. Tomsk: Tomsk State University.

United Nations. (2001). Indicators of Sustainable Development: Guidelines and Methodologies. New York, USA: United Nations Press.

World Economic Forum. (2014). The Global Competitiveness Report 2013-2014. Retrieved from http://www.weforum.org/issues/global-competitiveness

\section{Copyrights}

Copyright for this article is retained by the author(s), with first publication rights granted to the journal. This is an open-access article distributed under the terms and conditions of the Creative Commons Attribution license (http://creativecommons.org/licenses/by/3.0/). 